\title{
A new capitosaur from the Middle Triassic of Spain and the relationships within the Capitosauria
}

Josep Fortuny, Àngel Galobart, and Carles De Santisteban

Acta Palaeontologica Polonica 56 (3), 2011: 553-566 doi: http://dx.doi.org/10.4202/app.2010.0025

Capitosaurs were the largest and homogeneous group of Triassic temnospondyl amphibians with cosmopolitan distribution. However, their interrelationships are debated. The first capitosaur cranial remains found in the Iberian Peninsula were assigned to Parotosuchus; herein, a re-description of this material, together with information on other remains recovered from the same site, enables us to classify them as a new genus: Calmasuchus acri gen. et sp. nov. (Amphibia: Temnospondyli) from the early-to-middle Anisian (early Middle Triassic). This capitosaur had a combination of plesiomorphic and non-plesiomorphic characters, such as posterolaterally directed tabular horns, paired anterior palatal vacuities, and unique morphology of the lower jaw. By cladistic analysis, we propose a new phylogeny for the monophyletic capitosaurs. In the analysis, Capitosauria is supported by seven synapomorphies. Wetlugasaurus is the most basal member of the clade. The score of the Russian taxon Vladlenosaurus alexeyevi resulted in a clade including Odenwaldia and the latter taxa. The Madagascarian Edingerella is the sister taxon of Watsonisuchus. Finally, Calmasuchus acri, the new taxon described here, appears as a more derived form than Parotosuchus. The new genus is the sister taxon of the Cyclotosaurus-Tatrasuchus and Eryosuchus-Mastodonsaurus clades.

Key words: Temnospondyli, Capitosauria, Mastodonsauroidea, phylogeny, computed tomographic scanning, Anisian, Triassic, Spain.

Josep Fortuny [josep.fortuny@icp.cat] and Ángel Galobart [angel.galobart@icp.cat ], Institut Català de Paleontologia, Universitat Autònoma de Barcelona, Edifici ICP, Campus de Bellaterra s/n, 08193 Cerdanyola del Vallès, Barcelona, Spain; Carles de Santisteban [carlos.santisteban@uv.es], Departament de Geologia, Universitat de València, C/o Dr. Moliner 50, 46100 Burjassot, València, Spain. 
This is an open-access article distributed under the terms of the Creative Commons

Attribution License (for details please see creativecommons.org), which permits unrestricted use, distribution, and reproduction in any medium, provided the original author and source are credited.

FaF 